\title{
A Report on the "Global Integration of Ancient Chinese Books" Project
}

\author{
Project leader: Prof. Zheng Jiewen 郑杰文, Shandong University \\ Peter Wai Ming CHENG
}

\section{Part 1}

Zheng Jiewen is one of the few prestigious third generation scholars studying the traditional Chinese classics in China, coming after Feng Youlan, Ji Xianlin and Tang Yijie.

Professor Zheng has been studying the Pre-Qin scholars and has made remarkable achievements with regard to Mohism, the School of Diplomacy, and the School of the Minor-talks.

$\mathrm{He}$ is one the leading lights of $\mathrm{Zi}$ (a category for philosophical works, established in the first encyclopedia during the Han Dynasty) studies, and especially the study of Mohism, in China. His book The History of Mohism (中国墨学通史) has been placed in the National Social Sciences Foundation Library, and won first prize in the highest awards given for liberal arts disciplines by the Chinese government, the National College Humanities and Social Science Outstanding Achievements Awards. Articles were published in Guangming Daily, China Reading Weekly, Oriental Philosophy Research (Korean) and ten other academic journals, all noting its creativity. Ping-ti Ho of the University of Chicago, member of the Academia Sinica and American Academy of Arts and Sciences at that time, cited and spoke highly of this book. It is seen as a work that addresses previous gaps in the academic literature, because it is the first that elaborates on the general history of Mohism.

Professor Zheng is also a leader in the study of the School of Diplomacy and the School of the Minor-talks. His books, New Theory of the Warring State Strategies (战国策文新论), Theory of Chinese Ancient Political Strategists (中国古代纵横家 论), Study of Gui Guzi (鬼谷子研究), and Explanation of the Biography of $M u$ Tianzi (〈穆天子传〉通释), are all of tremendous academic influence. Due to his extraordinary achievements in Zi studies, in 2010 Professor Zheng was invited

Peter Wai Ming CHENG, Deputy Director (Research),

Senior Researcher, Jao Tsung-I Petite Ecole, The University of Hong Kong. pwmcheng[at]hku.hk

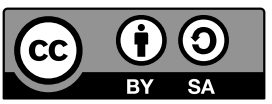


to work as the chief expert of the biggest liberal arts research project at the national level in China, Zibai Compilation and Research.

\section{Part 2}

Zibai Compilation and Research is a major project of the National Social Science Fund, established by the National Planning Office of Philosophical and Social Sciences at Shandong University. The final result of this project will be the Zibai Essential Editions, which will include hundreds of important $\mathrm{Zi}$ books, Zibai Rare Editions that will have hundreds of $\mathrm{Zi}$ rare editions, and Zibai Research Editions that will collect many research work on $\mathrm{Zi}$ studies.

The collections Zihai Special Volumes (子海特辑), Zihai Rare Editions (子海珍本 编), Zihai Rare Edition Images Catalogue (子海珍本编图录), Zibai Essential Editions (子海精华编), and Zibai Research Editions (子海研究编) will be published individually over a period of years. In 2011, three Zibai Special Volumes (子海特辑) were published by Phoenix Publishing House, and this included 20 unpublished papers written by Gao Heng, Luan Diaofu, Ding Shan, and Wang Xiantang. In 2013, the first volume of Zibai Rare Editions (子海珍本编), including 120 books in the Mainland Chinese volume and 50 books in the Taiwanese volume, were published by Phoenix Publishing House and Taiwan Commercial Press, respectively. Five kinds of $\mathrm{Zi}$ books have been digitized, including 47 block-printed editions and 47 autographs from the Song Ming period, 148 manuscripts from the Yuan Ming period, and 224 carved editions from the Ming period. There are thus a total of 503 of these works in the digital archive, representing $92.6 \%$ of the content, providing a resource of great academic value.

The first volume of Zihai Rare Editions (子海珍本编) was very well-received. Shandong University established a project called the Global Compilation of Ancient Chinese Books (hereinafter referred to as the Integration), enlarging the scope of target books from $\mathrm{Zi}$ to all four categories of ancient Chinese books. This project includes partnership not only with individuals and organizations in Taiwan, but also in Europe and America. In this way, the Integration will collect ancient books from all over the globe and publish them.

It is no accident that Shandong University has been entrusted with such an important project. Shandong University has always been very strong in its work in the liberal arts. In particular, it is known for its ability to organize projects that compile ancient documents and undertake thorough explorations of the ideas within them. Such efforts are supported by various academic teams that contain 
with numerous and highly specialized experts. With regard to the project considered here, an editorial board was set up drawing on staff from Shandong University along with 170 experts from other institutions, such as Nanjing University, Tokyo University, Howard University, the University of Munich, the University of Macau, National Taiwan University, Hong Kong Chinese University, and other universities from Hong Kong, Taiwan Macau, mainland China and the West. The resulting team was divided into three units working on the digitization of rare editions, compilation of essential editions and academic research.

Digitization is led by Professor Liu Xinming, who was hired by the Ministry of Culture in China as an expert on the inscriptions that appear on ancient bronzes and stone tablets. He is well-known in the field of cataloguing, literary criticism, and the identification of editions. Professor Liu is one of the main leading experts of the Integration and International Chinese Study Research Collaboration, and in this capacity presides over the cataloguing and digitization of the related books that are held overseas. Professor Liu has edited Zibai Rare Editions (子海珍本编) and Collection of Bibliographies in the Twenty-Five Histories (二十五史艺文经籍 志考补萃编) among other significant academic achievements, and he also works on philological theory and ancient stone inscriptions.

The compilation of essential editions is led by Professor Wang Chenglüe. Professor Wang helped Professor Wang Shaozeng in the compilation of the Shandong Literature Catalogue (山东文献书目), and an edition of the Records of Art and Literature in the Qing Dynasty (清史稿艺文志拾遗), and compiled the Collection of Various Editions of the Twenty-Four Histories (百衲本二十四史校勘记). Professor Wang also helped Professor Dong Zhian in compiling The Collected Works of the Han Dynasty (两汉全书), Integration of Important Books for the Biographies of the Characters Outside the Twenty-Five Histories (二十五史外人物总传要籍集 成), and The Four Categories of Books in Tang Dynasty (唐代四大类书). His own books include Picture on the Things of Mao's Song (毛诗品物图考), Notes About Pictures of Lisao (离骚全图校释), Zheng Xuan and Classics (郑玄与今古文经学), Research on Li Tao's Life and Works (李奉学行诗文辑考), New Notes on the History of the East Han Dynasty (后汉书新注), and Collection of Bibliographies in the Twenty-Five Histories (二十五史艺文经籍志考补萃编).

The research unit of the project is led by Professor Zheng Jiewen.

The three units outlined above have achieved significant results after five years of diligent work.

Following the publication of the first volumes of the Zibai Rare Editions (from both Mainland China and Taiwan), the Zihai Rare Editions Overseas Volume (Japan) 
(子海珍本编·海外卷 (日本) ) and Mainland Volume (Shanghai Library) (子海 珍本编・大陆卷 (上海图书馆) ), and will be published. The Zihai Rare Edition Overseas Volume (Japan) will include 150 books in 34 digitized $\mathrm{Zi}$ volumes from Japan's National Cabinet Document Library, National Diet Library, Housabunko Library, and Library of the Imperial Household Agency, Seikado Library, the University of Tokyo Library, and Waseda University Library. Mainland Volume (Shanghai Library) (子海珍本编・大陆卷（上海图书馆）) will be published in three batches, and contain 1,000 ancient books in total, and the Three Editions of Conspectus of Penal Cases (刑案汇览三编) will also be published, with these edited by Shen Jiateng.

In 2016, the first volume of the Zihai Essential Editions (子海精华编) came out, containing three million characters from a collection of nine different books. The Zihai Essential Edition (子海精华编) team has collected a total of 97 books, with the remaining 88 scheduled to be published soon.

The academic research unit is responsible for the Zibai Research Edition (子海研 究编). They are now working with overseas academics, as seen in the publication of Chinese version of Confucian Role Ethics by Professor Roger Thomas Ames, Probing into Zi Books (子书探微) by Wiebke Deneck, from Columbia University, A Study on Gui Guzi and Political Strategists (〈鬼谷子〉与纵横家研究) and Yilin and Ancient Culture Study (〈易林〉与上古文化研究) by Professor Hans van Ess, from the University of Munich.

\section{Part 3}

The Integration is in progress, and includes the following four parts.

1. Co-compilation of the Catalogue of Global Ancient Chinese Books (hereinafter referred to as the Catalogue). The Catalogue is the academic foundation of the Integration. Through the collaboration of members of the Global Consortium for Chinese Studies, the expert team will be able to obtain detailed information about the major book collections held by overseas institutions, gather and compile a catalogue of ancient Chinese books, publish it and then issue a digitized version.

2. The outcomes of the Integration. Based on the Catalogue the expert team will select books with the most ideological value and academic representativeness, digitize and selectively publish them. The final result will be serval times larger than the Complete Library in the Four Branches of Literature that was produced in the Qing Dynasty.

3. Database for the Integration. This database aims to collect ancient books from both inside and outside China, and especially rare editions. The database 
will be equipped with rigorous academic system and a refined collection of collated and noted ancient books, and will provide a powerful search function for users. The database will be divided into the following sub-databases: 1 . Database of the Catalogue of Global Ancient Chinese Books, 2. Database of the book images of Global Ancient Chinese Books, 3. Database of links to images on other servers (this will replace the first database after its completion). Together these sub-databases will offer the results of this project on the same platform.

4. Translation and other promotional work. Once the books have been selected and entered into the database, it is hoped that this project will influence the direction of scholars studying Chinese culture worldwide. One thousand books will thus be selected and then translated into modern Chinese and published outside of China. Two hundred books will be translated into foreign languages and published outside China, and this is also likely to influence the cultural choices of elite groups in other countries.

\section{Part 4}

Many ancient Chinese books are stored in collection agencies in Mainland China, but a large number remain in other areas due to historical reasons, among which there are books of great academic value. For example, among some 3,000 Song-Yuan Period ancient books, around 500 rare editions are stored in Taiwan. In addition to their academic value, these books have great value as antiques and artifacts.

Such items include the printed version of the Li He Poetry Anthology (李贺歌 诗编) on official document paper dates back to the end of the Northern Song / beginning of Southern Song, the Brief History of the East Capital (东都事略) home-printed by Cheng Sheren at Mount Mei during Southern Song Shaoxi Period, the 10-line-per-page version of Picture and Classification on Xuncius (纂图 分门类题注菂子) printed in Jianyang, New Compilation of Geography and Scenic Spots (新编方與胜览) printed in Jian'an in the third year of Xianchun, Xiaozhuan Notes on the Book of Loyalty (忠经管注) printed at the end of Southern Song, the 11-line-per-page version of Picture and Mutual Notes on Book of Changes (纂图互 注周易) printed in Jianyang during the Southern Song period, and Collection of Ouyang Xingzhou (欧阳行周文集) printed in Sichuan during the Song Dynasty. These books are of great significance for academic research. Moreover, when originally in circulation certain ancient books were segmented into several parts, and these parts stored in difference places. Fortunately, although the books are thus 
fragmentary in nature, by putting them together we can get most of their content, and in some case even the whole content. The first volume of the Zibai Rare Editions is a good example of such piecing together of ancient works. Academia Sinica in Taiwan was able to preserve 122 volumes of the Japanese manuscripts of the Second Edition of Chinese Medicine Encyclopedia in Dade (《大德重校圣济 总录》), while the Japanese Imperial Household Agency Library kept another 35 volumes from the Song period, and a further 37 volumes are stored in libraries in Mainland China. The project team thus gathered all these volumes during their digitization efforts, and so were able to provide very comprehensive data. As such, Professor Zheng believes that instead of keeping the books to themselves, book collection institutes, libraries and so on should contribute these resources to academic research efforts. This is why Professor Zheng advocates a complementary and integrated approach to the collection and study of ancient Chinese books, both in and outside China.

\section{Part 5}

As part of the Integration project the team of experts is devoted to the investigation, cataloguing and digitization of these ancient books, as well as the construction of a database, in order to meet current research trends. Since the 1990's, the construction of this ancient books database has been gaining speed, helped along by a number of such databases with high academic value that have been developed over the years. The basic Chinese ancient books database, developed by the Beijing Airusheng Digital Technology Research Center and published by Huangshan Publishing House, includes 10,000 works in 170,000 volumes of ancient books from the Qin to the Republican periods. It provides a public version that contains the full content and images from one or two important versions of each work. Overall, this database contains 1.7 billion Chinese characters, 12,700 editions, and 10 million pages of images.

The National Ancient Books' Preservation Center, relying on the large ancient collections of the National Library, co-operates with a microcopy center and transfers the ancient text to high-definition images, which are then used in the Chinese Ancient Book Resources Database. This now has images of rare and good editions of 10,975 volumes, 91,467 books, and 6,124,464 images, which account for around one third of the total number of good editions collected by China's National Library. Zhonghua Book Company also has a collection of recently-collated editions of ancient books in its Database of Ancient Books of Chinese Classics. The first volume collects 260 kinds of books texts from all four categories, as 
collated by Zhonghua Book Company, among which are The Twenty-Five Histories (二十五史), Consultancy (通鉴), Nerwly Organized Integration of Ancient Chinese Scholars (新编诸子集成), Notation of the Thirteen Confucian Classics by Qing Scholars (清人十三经注疏), Notes of Historical Materials (史料笔记从刊), Classical Chinese Literature Basic Books (中国古典文学基本丛书), and Ancient Buddhist Books and Records (佛教典籍选刊). The Ancient Books Preservation Center of China's National Library recently published a Database of Ancient Chinese Books as part of the national general survey. This is part of the Ancient Books Protection Plan, and it carried out for the first time a unified search for ancient books at the national level.

Although a valuable database for ancient Chinese books has been built up, based on those works in China, as yet there is now database featuring ancient books from outside the country. In the Global Integration for Ancient Chinese Books project the expert team will develop such a database based on the Catalogue and the final results of this project.

The database thus aims to collect ancient books from China and overseas, and especially rare editions. As noted earlier, this database will be based on a rigorous academic system and will include a collection of noted ancient books, and will provide a powerful search function. The database will be divided into the following sub-databases: 1. Database of the Catalogue of Global Chinese Ancient Books, 2. Database of the book images, 3. Database of links to images on other servers (which will replace the first database after its completion). There will be a physical database and virtual database, and together they will offer the results of the Integration project on the same platform.

The database of book images of Global Ancient Chinese Books is the catalogue containing information about books collected by the Integration. In the first stage the database collects around 190,000 different books. The information included in the database includes the serial number, title, number of volumes, author, version, form of arrangement, existing and lost volumes, collection institutes, and so on. As the project develops there will eventually be information on around 250,000 books, and the database will be connected to related databases both in and outside of China.

The database of book images of Global Ancient Chinese Books is also built as part of the Integration project. It contains images and information on selected books, mostly the good and rare editions. Shandong University has signed an agreement with The British Library, Bibliotheque Nationale de France, the China National Library, the Taipei Palace Museum, Housabunko Library, Seikado Library, the University of Tokyo Library, and the Russian State Library, and they will issue 
license agreements enabling the project to upload the original images of ancient books. In 2015 the International Sinology Research Center (hereinafter referred to as the Center) appointed Professor Wang Peiyuan as its chief, and twice sent a team to Russia to carry out cataloguing, selection, identification and digitization. The first batch of images included 600 rare editions stored at the Center, and 1,800 good editions stored in Shandong University Library. More will be included later. The search system of the database of the Catalogue of Global Ancient Chinese Books will be connected with the related book image database.

From a technical perspective, the aforementioned database constitutes two system: a catalogue database and a literature system. According to the current plan, 90,000 kinds of ancient Chinese books in 1.2 million volumes and 16.22 million pages will be included in the database, with a total of 8.61 million Chinese characters, and a data size of $1.813 \mathrm{~TB}$. The search system meets the Unicode international standard, and includes a very large set of Chinese characters, both traditional and simplified, as the search language. Moreover, it will also provide a major non-Chinese language environment, vague and specific search system, and online and offline versions for different users.

The Catalogue database will include comprehensive information on the books, such as name, sub-content, period, author, category, edition, and so on. By adopting text formatting, users can conveniently search for general information about the books using category name, period, and Pinyin. The database of book images will adopt the PDF graphic format. The original images will be shown to the users, which ensures both accuracy and practical value. At the same time, users can make notes with system, just like on paper books. These notes can then be saved separately, or along with the resources downloaded from the database.

The process of digitizing and integrating the collections of ancient Chinese books held outside of China outlined in this paper will provide systematic research data for sinologists worldwide, and provide a relatively comprehensive overview of this aspect of Chinese culture. 